\title{
Public Opinion Analysis of Road Accidents\&Review of Conventional and Combinational Driver Safety Methodologies with SelfLearning Algorithms
}

\author{
Tamilarasi $\mathbf{A}^{1}$, Sivabalaselvamani $\mathrm{D}^{2}$, Rahunathan $\mathbf{L}^{3}$, Adhithyaa $\mathrm{N}^{4}$ \\ ${ }^{1}$ Professor, Department of Computer Applications, Kongu Engineering College, Perundurai, Erode, India. \\ ${ }^{2}$ Associate Professor, Department of Computer Applications, Kongu Engineering College, Perundurai, Erode, \\ India. \\ sivabalaselvamani@gmail.com, \\ ${ }^{3}$ Associate Professor, Department of Computer Applications, Kongu Engineering College, Perundurai, Erode, \\ India. \\ ${ }^{4}$ JuniorResearch Fellow, Department of Computer Applications, Kongu Engineering College, Perundurai, Erode, \\ India.
}

\begin{abstract}
Article History: Received: 11 January 2021; Accepted: 27 February 2021; Published online: 5 April 2021
Abstract: Advanced driver assistance and accident detection system is significantlyneeded to ensure safety for drivers. Drowsiness detection, collision detection and various driver alert systems have penetrated into market with an aim to provide higher security for driver but due to population of vehicle and modification in structure of roads these system fails to answer safety problems that results in severe accidents.In this paper we provide accurate analysis of past recorded accidents in Tamil Nadu state and analysis of public opinion on Accident detection system is carried out using 1004 licensed persons under different ages in three cities (Coimbatore, Erode and Nilgiris) by focusing the major 10 parameters carrying 48 Questions. Findings and implications of this analysis is also discussed in this article. A thorough analysis of recent techniques that are used for AAD (Automatic Accident Detection) and road safety programmes that resolve the pre and post cautionary concerns of accidents in developing countries is addressed with the review of most 4 influencing algorithms in ITS for AAD.. 1 Vehicle Detection using Wheel arc Counter Detection Algorithm, 2 Enhancement of V2X Communication using MultiRAT,3Road Curvature Estimation using Circle Fitting Algorithm and4Driver Safety Systemis discussed in this paper. To understand recent computational challenges and extended areas of research in ITS, anhybrid approach of CNN with VANETs for accident detection has been suggested to enumerate the obtained accidental information.

Keywords: - Public opinion, Accident detection, Traffic detection, V2X, Autonomous vehicles, CNN and VANETs
\end{abstract}

\section{Acknowledgement}

We would like to thank Dr. V. Balusamy,Principal, Kongu Engineering College, for sharing his pearls of wisdom with us during the course of writing this article and Dr.P.Kiruthika, Assistant Professor, Department of English, Periyar University PG Extension Centre, Dharmapuri, for sharing her knowledge towards correcting the article that greatly improved the manuscript.

\section{Introduction}

India is a populated country that has second largest road transport network with around 1,15,435 km [82]. As usage of road transport is high, maintenance isalso extremely high.One of the key problems in the maintenance sector that is still not adequately handled by transport is maintaining road safety, which results around 1.77 lakh deaths per year in Indian road that is very higher than the number of deaths of all Indians in all wars [81].It shows that more concentration is needed to avoid accidents.

Driver alert system provides alerts to driver but there are very few systems that provide accident assistance.Reporting the incident to the concerned team with conditioned information is the matter of emergency in accident conditions. Sensitive information has to be passed to the nearest ambulance, health center, police station and the fire station if needed. Vehicle information that caused the accident, details of the driver and severity of the incident are to be transmitted for further action. The incident is considered to be sensitive based on the severity. In $90 \%$ of cases, the severity is defined with heavy weighted parameters like speed, angular velocity and direction of the source vehicle and target obstacle. Wu et al, considers Intersection, Distance and Speed-Distance for evaluation of vehicle-pedestrian near crash prediction [85]. We consider10 major parameters for public opinion analysis, Weather conditions, Road conditions, Driver fatigue and drunken driving, Excessive speed, Vehicle faults, Animal collision, Distracted driving, Young aged driving, Unexpected lane changing and Red light jumping.

The paper is structured as,Public opinion analysis with history of road accidents in Section II followed by section IIIwith a defined relationship, devices, various techniques and algorithms involved in accident detection and prevention. Section IV provides the suggested hybrid approach, Section V portrays results and discussion and Section VI is conclusion. 


\section{Public Opinion Analysiswith history ofroad accidents}

There are several researchers working on crash prediction to link real-time crash chance with traffic and roadways. Based on the motivation of reducing road accidental death that occurs in Indian roads andas the revision on technologies on VANETs and Machine Learning grows it is strongly believed that applying those will resolve the problem but due to huge road users and road structures it is not that much easy thing to implement in Indian roads. In order to identify the exact reason for accidental deaths, data was collected from 1004 road users out of which 382 female users and 622 female users. We have also collected many repository data from police department and Health \& welfare department.

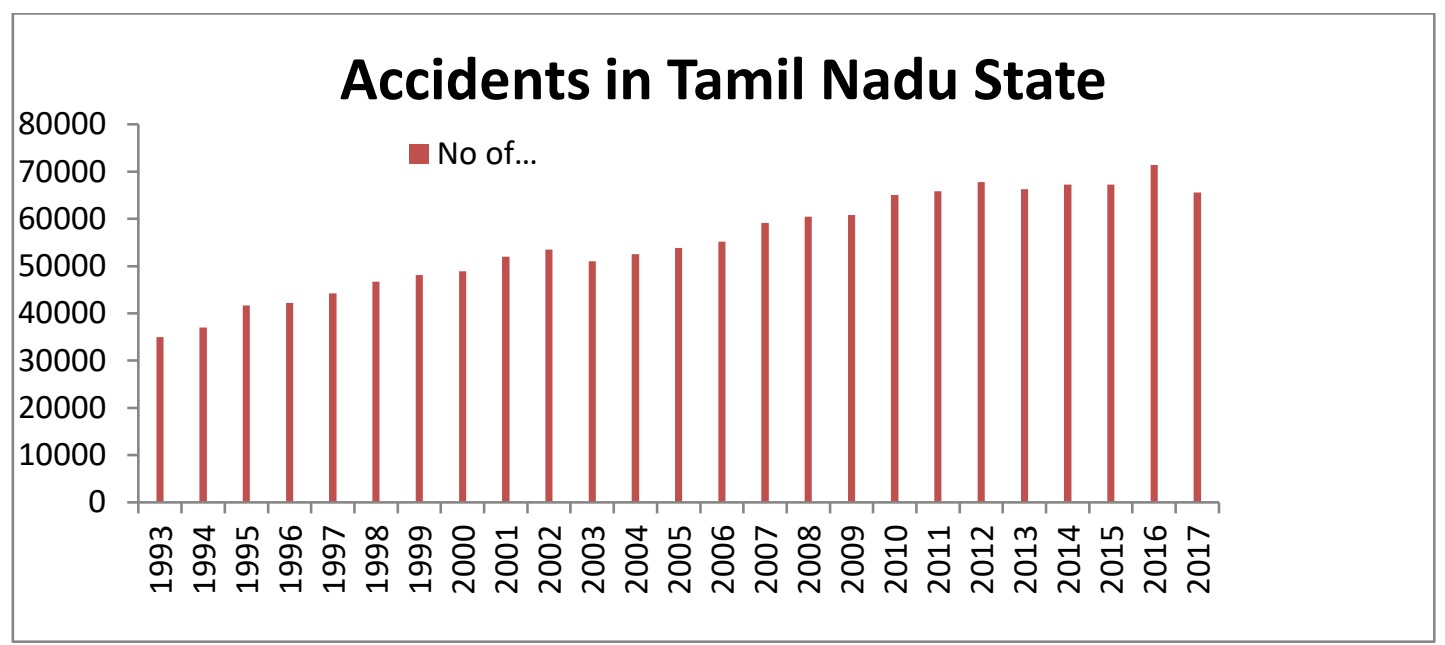

fig. 2.1.

The total number of accidents in Tamil Nadu urban and rural roads, which are recorded with SCRB, Chennai (responsible for data in police department) is shown in figure 1 which has the highest of 71,432 accidents in the year of 2016 and upon that the count is in and around 75 thousand approximately which is found once discussing with the police chief.

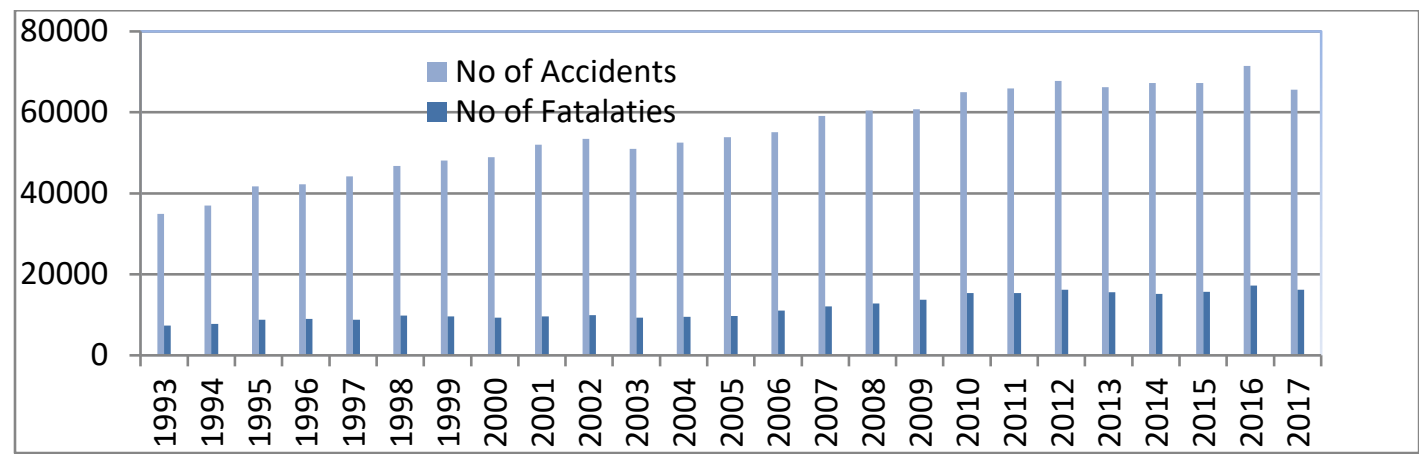

fig. 2.2

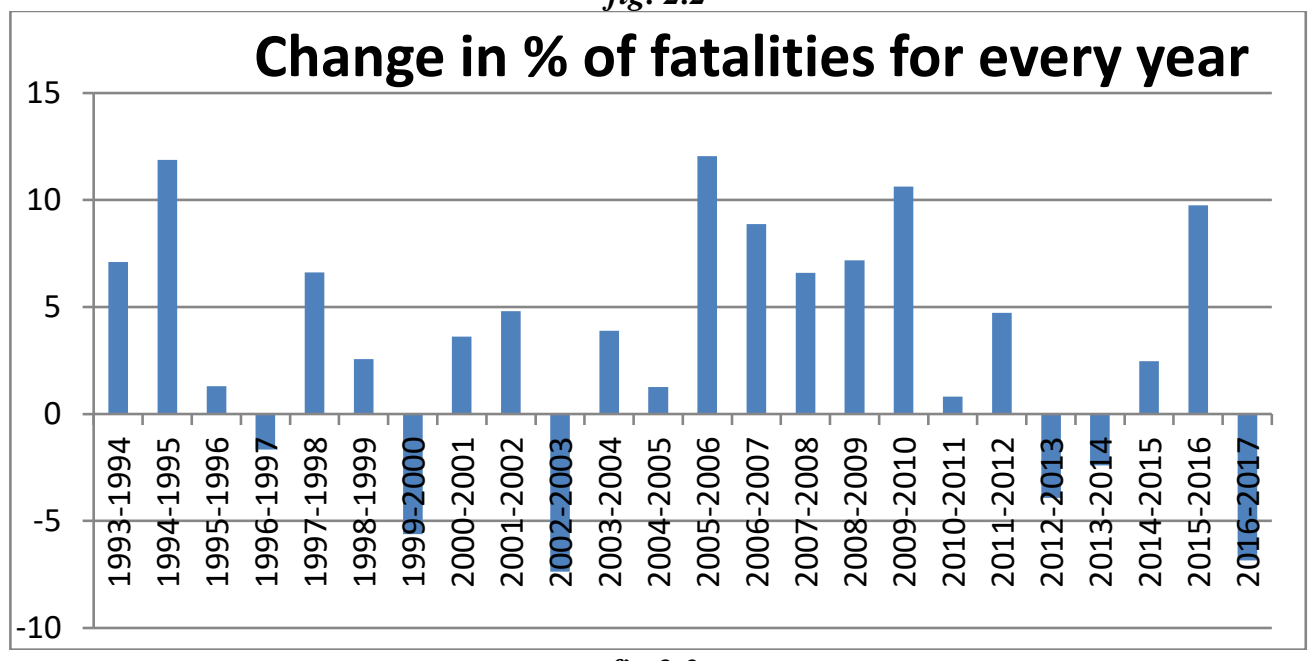

fig.2.3. 
It is observed that, there is a steady increase in the growth of fatalities due to accidents of $3.2 \%$ as an average of every year. 2003 has around 7\% lowest death rate recorded compared to 2002 has been seen as good scenario and it was not maintained because in the next consecutive year of 2016 it has found that $12 \%$ of increase compared to 2015. From this implications it can be concluded that the death rate due to accidents will vary accordingly year by year based on several parameters.

We classify accidents into four types based on injuries occurred in accidents, Fatalities, Severe injuries, Minor injuries and non-injuries.

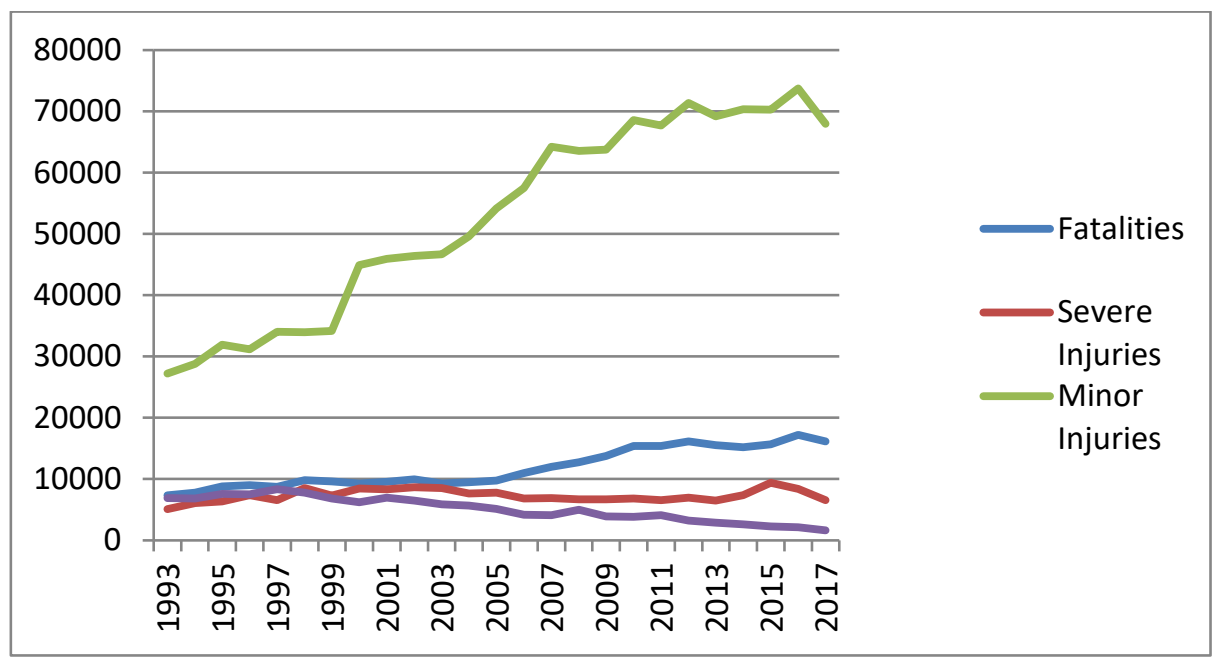

fig 2.4.

As compared to any other three factors, minor injuries are higher which also denotes that the accidents are still happening even after this much researches and implementations in road safety and vehicular technology and infact vehicle accidental death have multiplied by three times from 39,675 in 2003 to 90,729 in 2017. Tamil Nadu recorded second highest road accidents in India in 2017. A questionnaire is formed to collect the public opinion about road accidents which was collected from 1004 persons is given with the support values in table 2.1 .

\begin{tabular}{|r|c|c|}
\hline $\begin{array}{r}\text { Q } \\
\text { no. }\end{array}$ & Details & $\begin{array}{c}\text { Sup } \\
\text { port } \\
\text { value }\end{array}$ \\
\hline 1. & Avoiding road accidents due to weather is highly difficult & 84 \\
\hline 2. & Accidents due to fog will only happen in hills & 82.7 \\
\hline 3. & Curved roads has high probability of accidents & 81.6 \\
\hline 4. & U-Turns in hills are more dangerous crash counters & 82.2 \\
\hline 5. & Cracks and potholes can cause the driver to lose the control of the vehicle & 78.9 \\
\hline 6. & Inadequate guardrails on curves and overpasses causes upside-down accidents & 82 \\
\hline 7. & Placing construction materials and utility poles in a way obstructs a drivers & 81.1 \\
\hline 8. & Taking medicines during driving causes drowsiness & 80.7 \\
\hline 9. & Driver drowsiness will be extremely heavy after having full stomach food & 83.5 \\
\hline 10. & Crashes due to drowsy driving occurs mostly at night time & 81.3 \\
\hline 11. & Drunk and driving accidents will frequently occur in rural roads & 70.2 \\
\hline 12. & Aged drivers (45 to 70 yrs of age) has high risk of fatigue & 75.2 \\
\hline 13. & It is difficult to always drive within the speed limit & 68.2 \\
\hline 14. & Speeding always results in loss of vehicle control & 73.6 \\
\hline 15. & Speeding increases stopping distance once the driver perceives the danger & 73.6 \\
\hline 16. & Signal & 68.7 \\
\hline
\end{tabular}




\begin{tabular}{|c|c|c|}
\hline & injuries & \\
\hline 17. & Accidents due to speed will be physically high & 73.8 \\
\hline 18. & Failures of airbags deployment at necessary times will result in accident & 73.3 \\
\hline 19. & Improper condition of wiper in necessary/needed times causes crash & 72.6 \\
\hline 20. & Seats or seatbelts failure unexpectedly results in severe injuries & 73.9 \\
\hline 21. & Most animal collision accidents are due to dogs & 71.1 \\
\hline 22. & $\begin{array}{l}\text { Animal collision gives higher crash damage for two wheelers when compared } \\
\text { to four wheelers }\end{array}$ & 75.3 \\
\hline 23. & Honking makes the animal scary and avoids accidents & 73.9 \\
\hline 24. & Collision of an animal will not cause a fatal death for drivers & 71 \\
\hline 25. & $\begin{array}{l}\text { Since animals are most active around dawn ( } 4 \text { to } 6 \mathrm{am}) \text { and dusk (6 to } 11 \mathrm{pm}) \\
\text { drivers should be extra vigilant }\end{array}$ & 69.5 \\
\hline 26. & Usage of electronic devices distracts the driver & 69.1 \\
\hline 27. & Bad emotional state of the driver will result in aggressive driving & 69.5 \\
\hline 28. & Often driver gets distracted when other occupants needed attention & 69.5 \\
\hline 29. & Driver always gets distracted if they smoke while driving & 70.1 \\
\hline 30. & Teenage male drivers are most likely to speed & 68.5 \\
\hline 31. & $\begin{array}{l}\text { Most young drivers will refuse to wear safety equipments that causes severe } \\
\text { accidents }\end{array}$ & 68.6 \\
\hline 32. & Most of the young drivers don't know road rules & 68.3 \\
\hline 33. & Most of drunken drivers were young drivers & 68.3 \\
\hline 34. & Young lady drivers frequently break the road rules & 67.7 \\
\hline 35. & $\begin{array}{l}\text { Failure to perform a "shoulder check" to check blind spots will result in } \\
\text { accidents }\end{array}$ & 67.8 \\
\hline 36. & Un-Intimated lane changing causes accidents & 69.3 \\
\hline 37. & $\begin{array}{l}\text { Driving slowly in the left lane forces other drivers to travel at faster speeds to } \\
\text { change lane }\end{array}$ & 69.7 \\
\hline 38. & Rear end accidents occur mostly at night time & 69.7 \\
\hline 39. & Accidents due to job of an individual are higher (like delivery jobs) & 67.3 \\
\hline 40. & $\begin{array}{l}\text { Accidents caused by private vehicles are more when compared to public } \\
\text { vehicles }\end{array}$ & 68.1 \\
\hline 41. & Driver education reduces the accidents & 63.9 \\
\hline 42. & Road monitoring helps in reducing the traffic accident & 65.2 \\
\hline 43. & $\begin{array}{l}\text { It is necessary that all safety equipments are to be used even for small distance } \\
\text { driving }(<1 \mathrm{~km})\end{array}$ & 69 \\
\hline 44. & Road accidents is a huge threat to the human society & 65.1 \\
\hline 45. & Road accidents are preventable & 67.9 \\
\hline 46. & There is no particular accident detection system in our society & 70.7 \\
\hline 47. & $\begin{array}{l}\text { A alternative traffic control system designed especially for ambulance is } \\
\text { needed in India }\end{array}$ & 69.3 \\
\hline 48. & Road safety awareness camp is needed at regular intervals & 67.9 \\
\hline
\end{tabular}

Table 2.1

Support value is initially collected from public based on individual's score of that statement for 5 and then converted to 100 .

S.V for a Statement $=$ Sum of values of all the opinions of that statement $\quad * 20$

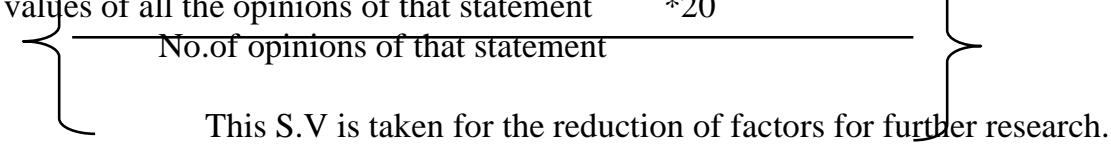




\section{Prevention and Detection of accidents}

\section{Theory behind prevention and detection of accidents}

The relative need of efficient driver alert system and automatic accident detection is an action of precaution and postulation of the accidents in road safety. To understandthe realistic relationship between prevention (Precaution) and detection (Postulation) of accidents the following theory has to be followed.

$$
\mathrm{D} \propto \frac{1}{\mathrm{P}}
$$

$\mathrm{P}$ is Prevention of Accidents andD is Detection of Accidents.

\section{Assistance from various devices for Accident Detection}

The devices involved in Advanced Driver Assistance System (ADAS) are Monocular camera, Stereo camera, Fish eye camera, Charge couple device camera, RADAR, LIDAR, MEMS, NEMS, Gyroscope, IR camera, EEG, GPS, GSM,Multimodal sensor, Vibration sensor, Speed sensor, Alcohol sensor, Proximity sensor, Ultrasonic sensor,Photonic mixer devices and so on. All these devices provide safety to driver but stillaccident persists due to failure of system or driver carelessness.Several accident detection techniques are available anditis activated when the driver is not able to get alert from ADAS and meet with an accident. When accident occurs,transforming theinformation from that accident spot to the rescue center for further action is the biggest research challenge in current days.

\section{Techniques and algorithms involved in Accident Assistance}

\subsection{Wheel Arch Counter Detection (WACD) algorithm}

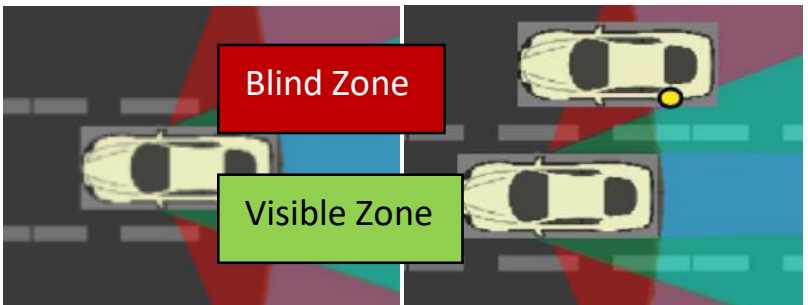

fig.3. $1 a$

fig. 3.1b

It was introduced by Dooley et al [1], On the rear side of the car, a fish eye camera is positioned to identify the target vehicle (TV) entering the blind zone using calibration technique and monitors the vehicle with the aid of the angular velocity and speed of that vehicle after entering the blind zone, as seen in Fig 1b. The data received from camera is classified using Adaboost classifying technique to identify the TV from 10-40m before vehicle enters into blind zone. Identification of all the zones was a challenging research in which Google cars has produced high potential output using mounted-LIDAR units.

The vehicle safety mechanism with the help of Suspension and Control System (SCS) is an approach of Automatic Cyber Physical Systems (ACPS) that provides knowledge to the vehicle in all zones and is proposed by Naufal et al [75].It uses four proximity sensors to detect moving vehicle from front, back and sideways [75]. $\mathrm{A}^{2} \mathrm{CPS}$ Engine is an embedded device fixed in the vehicle that receives data from sensors, other vehicle and from information centre. It takes all computational work and providesIncident Zone Warning (IZW), a safety mechanism used to provide alerts based on the features extracted from the proximity sensors. A few other computer vision methods that are used in road safety applications in Table 2.

Table 2-Some of the techniques used in road safety applications that can be implemented in ITS.

\begin{tabular}{|c|c|c|c|}
\hline Purpose & $\begin{array}{l}\text { Author } \\
\text { name }\end{array}$ & $\begin{array}{c}\text { Method } \\
\text { Algorithm }\end{array}$ & Description \\
\hline \multirow{3}{*}{$\begin{array}{l}\text { Vehicle } \\
\text { Detection }\end{array}$} & $\begin{array}{l}\text { Wang et al } \\
{[43]}\end{array}$ & \begin{tabular}{lr}
\multicolumn{1}{c}{ Radar } & and \\
Vision & fusion \\
Algorithm &
\end{tabular} & $\begin{array}{l}\text { mmw-Radar and } \\
\text { monocular camera is } \\
\text { used to identify the } \\
\text { vehicle using a the } \\
\text { proposed algorithm. }\end{array}$ \\
\hline & $\begin{array}{r}\text { Shyr-Long } \\
\text { Jeng et al [29] }\end{array}$ & \begin{tabular}{lr}
\multicolumn{2}{c}{ Inverse } \\
Synthetic & Aperture \\
Radar & (ISAR) \\
Algorithm &
\end{tabular} & $\begin{array}{l}\text { On the roadside, } 2 \mathrm{D} \\
\text { FMCW radar is used to } \\
\text { measure the speed and } \\
\text { length of the crossing } \\
\text { car. }\end{array}$ \\
\hline & $\begin{array}{l}\text { Dooley et al } \\
\text { [1] }\end{array}$ & $\begin{array}{c}\text { Wheel Arch } \\
\text { Counter Detection }\end{array}$ & $\begin{array}{c}\text { Proposed a Blind } \\
\text { Zone Detection Method }\end{array}$ \\
\hline
\end{tabular}




\begin{tabular}{|c|c|c|c|}
\hline & & & using fish-eye camera. \\
\hline & $\begin{array}{l}\text { Fan and Zhu } \\
\text { [58] }\end{array}$ & $\begin{array}{l}\text { A New Vehicle } \\
\text { Separation Method }\end{array}$ & $\begin{array}{l}\text { Problem } \\
\text { overlapping of the } \\
\text { vehicles in on-road } \\
\text { videos is addressed and } \\
\text { handled with fourier } \\
\text { descriptor }\end{array}$ \\
\hline & $\begin{array}{r}\text { Kosaka } \\
\text { Ohasi [70] }\end{array}$ & $\begin{array}{l}\text { CenSurE and } \\
\text { SVM }\end{array}$ & $\begin{array}{l}\text { Vehicle detection } \\
\text { using Blob data that is } \\
\text { manipulated using } \\
\text { CenSurE are received } \\
\text { from the fixed } \\
\text { monocular camera and } \\
\text { classified using SVM }\end{array}$ \\
\hline & $\begin{array}{l}\text { Dong et al } \\
{[34]}\end{array}$ & $\begin{array}{l}\text { Enhanced } \\
\text { detector algorithm } \\
\text { adaptive to parking }\end{array}$ & $\begin{array}{l}\text { The AMR sensor is } \\
\text { used both in usual and } \\
\text { unnatural situations to } \\
\text { identify the car. }\end{array}$ \\
\hline \multirow{4}{*}{$\begin{array}{l}\text { Accident } \\
\text { Detection }\end{array}$} & $\begin{array}{l}\text { Fogue et al } \\
{[16]}\end{array}$ & \begin{tabular}{l}
\multicolumn{1}{c}{ OBU with } \\
VANETs and \\
configured DAU
\end{tabular} & $\begin{array}{l}\text { OBU is introduced } \\
\text { to get the accidental } \\
\text { information and pass it } \\
\text { by VANET for } \\
\text { immediate action }\end{array}$ \\
\hline & $\begin{array}{c}\text { Singh } \\
\text { Mohan [24] }\end{array}$ & \begin{tabular}{ll}
\multicolumn{1}{c}{ One } & Class \\
Vector & Help \\
Machine &
\end{tabular} & $\begin{array}{l}\text { The snaps for } \\
\text { processing are taken } \\
\text { with the aid of security } \\
\text { videos to identify the } \\
\text { accident identification. }\end{array}$ \\
\hline & $\begin{array}{l}\text { Thomas et al } \\
\text { [30] }\end{array}$ & \begin{tabular}{l}
\multicolumn{1}{c}{ Video } \\
summarization \\
framework
\end{tabular} & $\begin{array}{l}\text { A novel method } \\
\text { reducing the cost } \\
\text { function to provide the } \\
\text { summarized report of } \\
\text { accidents }\end{array}$ \\
\hline & $\begin{array}{l}\text { Nguyen et al } \\
{[45]}\end{array}$ & \begin{tabular}{l}
\multicolumn{1}{c}{ Video } \\
condensation \\
algorithm
\end{tabular} & $\begin{array}{l}\quad \text { Proposed a new } \\
\text { method for ordering the } \\
\text { Minimum number } \\
\text { frames of a video which } \\
\text { provides maximum } \\
\text { understanding of the } \\
\text { accident. }\end{array}$ \\
\hline \multirow{3}{*}{$\begin{array}{l}\text { Obstacle } \\
\text { Detection }\end{array}$} & $\begin{array}{l}\text { Kumari et al } \\
\text { [33] }\end{array}$ & $\begin{array}{l}\text { Joint V2V and } \\
\text { Long Range Radar } \\
\text { (LRR) in a single } \\
\text { carrier Band }\end{array}$ & $\begin{array}{l}\text { mm-Wave radar is } \\
\text { used for LRR and } \\
\text { DSRC std is combined } \\
\text { for obstacle detection }\end{array}$ \\
\hline & $\begin{array}{l}\text { Nyamagod } \\
\text { [51] }\end{array}$ & $\begin{array}{c}\text { Real time } \\
\text { Obstacle Detection }\end{array}$ & $\begin{array}{l}\text { FMCW radar is used } \\
\text { to measure the obstacle } \\
\text { on road and provides } \\
\text { the conceptual } \\
\text { information. }\end{array}$ \\
\hline & $\begin{array}{l}\text { Wang et al } \\
{[62]}\end{array}$ & $\begin{array}{l}\text { 1T2R, Ray } \\
\text { Tracing Technique }\end{array}$ & $\begin{array}{l}\text { FMCW radar is used } \\
\text { with one transmitter and } \\
\text { two receiver concept for } \\
\text { using multipath } \\
\text { directions using ray } \\
\text { tracing technique. This } \\
\text { technique helps in } \\
\text { covering most of the }\end{array}$ \\
\hline
\end{tabular}




\begin{tabular}{|c|c|c|c|}
\hline & & & obstacles on road \\
\hline & $\begin{array}{l}\text { Dairi et al } \\
{[42]}\end{array}$ & $\begin{array}{l}\quad \text { Deep } \begin{array}{r}\text { Stacked } \\
\text { encoders }\end{array} \\
\text { Auto } \\
\text { (DSA)- k-NN }\end{array}$ & $\begin{array}{l}\text { A stereo vision } \\
\text { camera is used to } \\
\text { capture the data and } \\
\text { DSA is implemented as } \\
\text { the solution for the } \\
\text { problem for anomaly } \\
\text { detection to detect } \\
\text { obstacles. }\end{array}$ \\
\hline $\begin{array}{l}\text { Animal } \\
\text { Detection }\end{array}$ & $\begin{array}{l}\text { Sharma and } \\
\text { Shah [4] }\end{array}$ & $\begin{array}{c}\text { Cascade } \\
\text { Classifier and HOG }\end{array}$ & $\begin{array}{l}\text { Proposed to avoid } \\
\text { the collision of animal. }\end{array}$ \\
\hline $\begin{array}{c}\text { Lane } \\
\text { Detection }\end{array}$ & $\begin{array}{l}\text { Xing et al } \\
{[10]}\end{array}$ & \begin{tabular}{lr}
\multicolumn{1}{c}{ ACP } & Parallel \\
Theory, & Lane \\
Detection & \\
Framework & \\
\end{tabular} & $\begin{array}{l}\text { Multimodal sensors } \\
\text { are used to detect the } \\
\text { lane keeping task. }\end{array}$ \\
\hline \begin{tabular}{l}
\multicolumn{1}{c}{ Facial } \\
Expression \\
Recognition
\end{tabular} & $\begin{array}{l}\text { Majunder et } \\
\text { al [17] }\end{array}$ & \begin{tabular}{l}
\multicolumn{2}{c}{ Automatic } \\
Facial Expression \\
Recognition system \\
(AFERS) - SOM \\
classifier
\end{tabular} & $\begin{array}{l}\text { A novel deep } \\
\text { network framework is } \\
\text { created to indentify the } \\
\text { facial expression with } \\
\text { the help of geometric \& } \\
\text { binary pattern, auto } \\
\text { encoders and classifier. }\end{array}$ \\
\hline \begin{tabular}{l}
\multicolumn{2}{c}{ Automated } \\
Driving in \\
Highway
\end{tabular} & $\begin{array}{l}\text { Noh and An } \\
\text { [22] }\end{array}$ & $\begin{array}{c}\text { Decision } \\
\text { Making Framework }\end{array}$ & \begin{tabular}{l}
\multicolumn{2}{c}{ Proposed a decision } \\
making system using \\
various devices for \\
situation assessment \\
and decision making.
\end{tabular} \\
\hline & $\begin{array}{l}\text { FIlonenko et } \\
\text { al [31] }\end{array}$ & \begin{tabular}{l}
\multicolumn{2}{c}{ Background } \\
subtraction method, \\
Boosted using \\
CUDA
\end{tabular} & $\begin{array}{l}\text { High resolution } \\
\text { image is taken from the } \\
\text { surveillance video to } \\
\text { identify the smoke in it } \\
\text { using CPU+GPGPU. }\end{array}$ \\
\hline $\begin{array}{c}\text { Fog } \\
\text { detection }\end{array}$ & $\begin{array}{l}\text { Gallen et al } \\
{[41]}\end{array}$ & $\begin{array}{l}\text { Back Scattered } \\
\text { Veil Detection \& } \\
\text { Halos Detection }\end{array}$ & $\begin{array}{l}\text { Fog is detected from } \\
\text { the image based on the } \\
\text { light source emitted } \\
\text { from the vehicle and in } \\
\text { street lamps. }\end{array}$ \\
\hline $\begin{array}{l}\text { Pedestrian } \\
\text { Tracking }\end{array}$ & $\begin{array}{l}\text { Kwak et al } \\
{[46]}\end{array}$ & $\begin{array}{l}\text { Weber- } \\
\text { Fechner's law, Real } \\
\text { time online learning }\end{array}$ & $\begin{array}{l}\text { Proposed } \\
\text { algorithm with two } \\
\text { methods to detect } \\
\text { pedestrians in different } \\
\text { seasons. Weber's law is } \\
\text { used to determine the } \\
\text { season. }\end{array}$ \\
\hline $\begin{array}{l}\quad \text { Driver } \\
\text { Fatigue } \\
\text { Detection }\end{array}$ & $\begin{array}{l}\text { Mandal et al } \\
\text { [63] }\end{array}$ & \begin{tabular}{lr}
\multicolumn{1}{c}{ A } & fusion \\
algorithm & and \\
Spectral & Regression
\end{tabular} & $\begin{array}{l}\text { PERCLOS[96] is } \\
\text { defined as robust } \\
\text { continuous level eye } \\
\text { opening and the } \\
\text { threshold is set to it. To } \\
\text { approximate the eye } \\
\text { condition, the Fusion } \\
\text { algorithm is used. }\end{array}$ \\
\hline \begin{tabular}{l}
\multicolumn{1}{c}{ Road } \\
Curvature \\
Estimation
\end{tabular} & Lee et al [13] & $\begin{array}{c}\text { Circle fitting } \\
\text { Algorithm, SVD }\end{array}$ & $\begin{array}{l}\text { In critical visibility } \\
\text { conditions, a new } \\
\text { approach is proposed to } \\
\text { find the curvature of the }\end{array}$ \\
\hline
\end{tabular}




\begin{tabular}{|c|c|c|c|}
\hline & & & lane. \\
\hline $\begin{array}{l}\text { Enhanceme } \\
\mathrm{nt} \text { of V2X } \\
\text { communication }\end{array}$ & $\begin{array}{l}\text { Lianghai et al } \\
\text { [14] }\end{array}$ & Multi-RAT & $\begin{array}{l}\text { Uplink and } \\
\text { downlink Latency is } \\
\text { measured in unicast and } \\
\text { multicast situations to } \\
\text { improve the V2X } \\
\text { communication. }\end{array}$ \\
\hline $\begin{array}{l}\quad \text { Collision } \\
\text { Avoidance } \\
\text { System }\end{array}$ & \begin{tabular}{l}
\multicolumn{2}{c}{ Sivakumar } \\
and mangalam \\
{$[48]$}
\end{tabular} & $\begin{array}{l}\text { A new vehicle } \\
\text { collision avoidance } \\
\text { system }\end{array}$ & $\begin{array}{l}\quad \text { Radar and speed } \\
\text { sensors are used to } \\
\text { include the vehicle } \\
\text { crash avoidance } \\
\text { framework in the } \\
\text { proposed closed loop } \\
\text { architecture. }\end{array}$ \\
\hline
\end{tabular}

The speed factor plays an important role in the study of the causes of accidental deaths; fifty drivers were recruited by Charlton and Starkey to analyze the driver speed choice and it was found that the mean speed is normal among all drivers in varying road situations [93]. Prototype willingness model is developed by Preece et al. [92] to identify fast driving and willingness in text driving is conducted in IBM SPSS Version 24 form the data received from 183 licensed drivers of 17-25 years old drivers and found that most of the positive attitude young drivers were protagonists. Several other factors that cause accidents are red light running, fog or snow, pedestrian crossing, collision of the animal, driver fatigue, multiple vehicle collision, brake failure, unlicensed driving, high beams in $\mathrm{NH}$ and $\mathrm{SH}$, distracted driving (not following traffic rules),speeding in turns and un safety stunts[24][30][41][45][63][95][83][86][98][100].

Animal detection technique using Computer Vision (CV) is proposed by Sharma and Shah [4]. This system has major role in densely populated city where animals like dogs, cows, monkeys and donkeys are large in number. In the CV process, the Histogram of Directed Gradients (HOG) is used to define the image characteristics [4]. It is trained under 2200 images. It solves big issue with less accuracy.Farid et al developed Safety Performance Function that computes crash counts for rural areas in four states [84] and one of the hardest predictive problems is critical night time accidents[99] thatoccurbecause of dangerous curves when driver is unaware of it. These curves are highly severe at worst climatic conditions like fog. 


\subsection{Road Curvature Estimation using Circle Fitting Algorithm}

Lee et al [13] introduced a method for estimation of road curvature using W-Band FMCW RADAR and Circle FittingAlgorithm that works in all possible critical conditions.The minimum orthogonal squares to minimize the sum of squares in the algorithm of circle fitting are given by

$$
F=\sum_{\mathrm{i}=1}^{\mathrm{n}} \mathrm{f}_{\mathrm{i}}^{2}
$$

Where $\mathrm{f}$ can be defined by geometric and algebraic models. Lee et al uses algebraic model, the popular algebraic equation for Circle Fitting Algorithm is

The minimization of the simpler function is

$$
A\left(x^{2}+y^{2}\right)+B x+C y+D=0
$$

$$
F(A, B, C, D)=\sum_{i=1}^{n}\left(A z_{i}+B x_{i}+C y_{i}+D\right)^{2}
$$

Where $1 /\left(B^{2}+C^{2}-4 A D\right)=1$ and function $\mathrm{F}$ in matrix is given by

$$
F=\|\mathbf{X A}\|^{2}=\mathbf{A}^{T}\left(\mathbf{X}^{T} \mathbf{X}\right) \mathbf{A}
$$

$\mathrm{A}$ is parameter vectors and $\mathrm{X}$ is $\left(\mathrm{z}_{\mathrm{i}}, \mathrm{y}_{\mathrm{i}}, \mathrm{Z}_{\mathrm{i}}\right)$. Lee et al uses function $\mathrm{F}$ with time varied vehicle dynamics as main input that is computed by Controller Area Network (CAN) and provided as input for radar sensor through CAN bus. The procedure provides $10-17 \%$ more accurate prediction compared to map data.

\subsection{Driver Safety System}

Driver Safety System (DSS) fall in two categories, Active and Passive Safety Systems (ASS and PSS). ASS provides Advanced Driver Assistance Systems (ADAS) that provide assistance by automatic collision control, braking and lane keeping. PSS are air bags and seat belts kukkala et al [79]. Camera used in computer vision technique is of two major types one is monocular (have only single lens) and other is stereo (more than 2 lens). Stereo cameras provide 3-D data by combining two or more images captured from various lens and it is mainly used for ASS. There are other devices that are used to get input data for ADAS and Accident Detection System (ADS) like IR cameras, LIDAR, RADAR, Ultrasonic sensors and photonic mixer devices. Each pixel of the frame is represented in the form of matrix data. ADAS processes these data around $60 \mathrm{fps}$ in which each frame contains 3 channels (RGB).

It undergoes various processes, such as segmentation, identification and monitoring of objects, measurement of depth and control of structures. Machine learning algorithms such as LR, Gradient-Decent, SVM, k-NN, ANN and CNN gain from ADAScomputing[79].A driver fatigue recognition model works with featuresextracted from ECG and EEG is proposed by yang et al [2]. Hidden Markov Model (HMM) is used to compute Dynamic Bayesian Network (DBN) at various time stamps is the Collection of Static BayesianNetwork (SBN) that is interconnected, the relationship that interconnects SBN is found using $1^{\text {st }}$ order HMM whileDBN classifies output to alert the driver. The importance of Electroencephalography in Sleepiness Detection System (ESDS) is given by Balandong et al [80]that act as interface between the human brain and control unit. EEG uses electrodes, these electrodes are fixed at nearest part of human brain to measure EEG signals[80] that extracts features from f8-electrode of EEG then used for SVM and Bayes for supervised learning to provide higher results.

Six key classified features used to define performance include different SDS techniques 1)subjective assessments 2) vehicle-based systems 3) behavior-based driver systems 4) Sleep-Wake mathematical models (MMSW) dynamics 5) human physiological signal-based systems 6) combinations of one or more of these techniques[80]. The conventional technique used to measure the level of sleepiness of the driver and steering wheel movement is the Karolinska Sleepiness Scale (KSS), percentage of eye close (PERCLOS), BioMathematical models are the techniques that plays a major role in the EEG evolving models.

\subsection{Autonomous Vehicles}

Deployment of software and electronic innovations in automotive industryfor connected vehicles is surveyed by siegel et al [78]. Applications of RADAR and LIDAR towards perception to find angular velocity of vehicle are used in autonomous vehicles which in turn increases the production of vehiclewith the aim to satisfy and safeguard the customers. RADAR Sensory methods are emerging with luxurious monster vehicle producer like Tesla, Google-Autonomous Vehicle, BMW and Benz where the connectivity of autonomous vehicles of inter and intra vehicle is important in designing of any autonomous vehicles. Sharing of sensor and actuator data is most needed in intra vehicle connectivity, whereas inter vehicle networks share the critical orderly information to another vehicle through VANETs. IEEE $802.11 \mathrm{P}$ is the unique communication protocol used in $\mathrm{V} 2 \mathrm{X}$ applications. 


\subsection{Enhancement of V2X Communication using Multi-RAT}

Vehicle to everything communication provides high reliability in processing important information in 5G Cellular networks. Single transmission techniques like LTE-Uu or PC5 will not help vehicle to everything communication, so a Multi radio access technique is introduced by J. Lianghai et al [14]. For Multi-RAT, a hybrid uplink mechanism is designed to boost reliability, it is designed to accept both LTE-Uu and PC5 packets in such a manner that OBU allows to relay the signal from the vehicle to the uplink.

Accident detection is computed using On-Board Unit (OBU) which passes accidental information using VANET to reach the concern [16]. Ki and Lee developed a model to predict accident at intersections using image captured charge couple device camera and feature extracted from moving vehicle is passed to ARRS model [7]. ARRS model analysis and evaluation of captured image is carried out with standard DVR to record and send information from AMP to TMC. Three major steps taken in this algorithm are vehicle extraction, feature extraction and detection of accidents to compute acceleration, position, area detection and compared with threshold to formulate the incident. In a recent paper Yaun and Abdel-Aty proposed a method to identify the accidents at Intersections and Intersection entrances [86]. Some of radar, lidar and sensory methods available are listed in Table 2.

\subsection{Traffic Detection (TD)}

The road congestion detectionto control the level of congestion is proposedto overcomemany traffic prediction techniques that failed to support the flow of traffic is provided byKalamaras et al [77]. As a parametric model, autoregressive integrated moving average (ARIMA) is used and k-NN, SVR is used as a non-parametric model to measure the efficiency of both models for traffic prediction. The accuracy of prediction is carried out by normalized root means square error.

An IoT cloud system to provide the traffic analysis is introduced by celesti et al [76]. Fixed sensors sometimes fail to send data through $4 \mathrm{G}$ network. This system sends data directly from vehicle to cloud with the help of IoT. Cloud system receives data and processes using \#openGTS to provide information about traffic to the passers in the same route with detailed information through GPS. A visual analytics tool is developed and maintained in the cloud server.

\section{Hybrid approach (CNN inVANETS)}

Convolution neural network has large number of parametersand this serves as an efficient approach in any kind of recent decision making system. Deep learning technique of Convolution Neural Network is used in computer vision and In the NLP method, the Recurrent Neural Network is used. An powerful method of crash prevention would be the combination of the CNN in Vehicular ad-hoc network to make crucial decisions in accident circumstances.

In the recent days most of the computer vision techniques follow CNN. Pixels of an image is represented as value matrix, based on the intensity of a particular pixel, the resulted huge matrix is given as input to convolution layerin Image Recognition (IR) problem. System uses 3D volumes of neurons (Width*Height *Depth) for further computation,For the identification of car license plates, a CNN-based MD-YOLO system has been implemented. The prediction of rotation angle and intersection over union is used to treat real-time conditions and to achieve better results [3]. Deep learning method is implemented in the framework for lane detection using multi model sensors that is capable of receiving the input in various situations [10]. The principle of computational experiments and simultaneous execution (ACP) is used to develop this method to understand, implement and test the lane detection mechanism in artificial society[10]. In CNN, input layer, convolution layer, induction layer, pooling layer, and output (fully connected) layer, there are usually five layers. Others are opaque layers, except for input and output layers.

The output obtained from the CNN chooses to trigger the contact channel. The simplified crash details would be transmitted from the car to everything through the contact channel (V2X). In Vehicle to Everything communication there are several issues that are still not properly addressed in VANET. They are congestion of data from Vehicle to Vehicle (V2V), security of the vehicle data when it is connected to everything which will make the VANET to perform poor. To solve this, all the vehicles should need to get connected only through the base station; warning messages are preferable from the base station to avoid accidents. Activation of vehicle to vehicle communicationwithout the support of base station should only beafter the accident to ensure high level security in VANETs. Deep learning and hybridization techniques that are applied in the field of Transportation Systems andDriver Technology will be the enhancement of ITS. 


\section{Results and Discussion}

As a part of opinion analysis in this paper, it is found that the support value received for Q1 is $84 \%$ and after that there was the steady decrease in the support value for each and every question. This also shows that people in Tamil Nadu state are little careless about road accidents and thus recorded the second highest road accident fatalities in 2017 among Indian states.

In DSS,Driver Drowsiness Detection (DDD) model developed by Li and Chung [21] used to detect drowsiness produces $96.15 \%$ accuracy that is higher than any other Drowsiness detection model and acceptance of driver alert system by driver is assessed by Rehman et al and produced 85\% variation in results [90] which gives very low results when compared to Li and Chung[21]. The study of Pylkkonen et al [88] with 53 truck drivers in the intervention to provide the sleepiness countermeasures is failed and proves that driver education is not the sufficient measure for driver sleepiness.

These two results infer us that neither driver education nor driver alert system is sufficient to protect drivers. Accidents are exceptional and even though there are high end auto pilot cars like Tesla s model and Benz F 015, there is still a huge gap in prevention of accidents and it has been proved once Tesla $S$ model failed to protect its driver who met with an accident in auto pilot mode. Thus in order to prevent accident an exceptional hybrid model is suggested in this paper.

\section{Conclusion}

This paper provides a detailed study to clarify the significance of the accident warning mechanism in Tamil Nadu. Various devices, techniques and methodologies that are used in ITS is detailed in this review with the most 4 influencing algorithms in the ITS which is more popular in various developed countries and several experimental resultsDifferent papers demonstrate that, using the new algorithms and processors such as GPGPUs, the standard computer vision approach can produce more accurate and precise performance.Based on the result of this study the hybrid approach of CNN in VANETs considering security could be the best research suggestion to avoid accidents.

\section{References}

1. D. Dooley, B. McGinley, C. Hughes, L. Kilmartin, E. Jones, and M. Glavin, "A Blind-Zone Detection Method Using a Rear-Mounted Fisheye Camera With Combination of Vehicle Detection Methods," IEEE Transactions on Intelligent Transportation Systems, vol. 17, no. 1, pp. 264-278, Jan. 2016.

2. G. Yang, Y. Lin, and P. Bhattacharya, "A driver fatigue recognition model based on information fusion and dynamic Bayesian network," Information Sciences, vol. 180, no. 10, pp. 1942-1954, May 2010.

3. L. Xie, T. Ahmad, L. Jin, Y. Liu, and S. Zhang, "A New CNN-Based Method for Multi-Directional Car License Plate Detection," IEEE Transactions on Intelligent Transportation Systems, vol. 19, no. 2, pp. 507-517, Feb. 2018.

4. S. U. Sharma and D. J. Shah, "A Practical Animal Detection and Collision Avoidance System Using Computer Vision Technique,” IEEE Access, vol. 5, pp. 347-358, 2017.

5. M. Quintana, J. Torres, and J. M. Menendez, "A Simplified Computer Vision System for Road Surface Inspection and Maintenance," IEEE Transactions on Intelligent Transportation Systems, vol. 17, no. 3, pp. 608-619, Mar. 2016.

6. S. R. E. Datondji, Y. Dupuis, P. Subirats, and P. Vasseur, "A Survey of Vision-Based Traffic Monitoring of Road Intersections," IEEE Transactions on Intelligent Transportation Systems, vol. 17, no. 10, pp. 2681-2698, Oct. 2016.

7. Y.-K. Ki and D.-Y. Lee, "A Traffic Accident Recording and Reporting Model at Intersections," IEEE Transactions on Intelligent Transportation Systems, vol. 8, no. 2, pp. 188-194, Jun. 2007.

8. Vasudev and D. Das, "A trust based secure communication for software defined VANETs," in 2018 International Conference on Information Networking (ICOIN), Chiang Mai, 2018, pp. 316-321.

9. E. O. Y. Jiang, "Acting Together: Joint Pedestrian Road Crossing in an Immersive Virtual Environment," p. 2.

10. Y. Xing et al., "Advances in Vision-Based Lane Detection: Algorithms, Integration, Assessment, and Perspectives on ACP-Based Parallel Vision," IEEE/CAA Journal of Automatica Sinica, vol. 5, no. 3, pp. 645-661, May 2018.

11. [11]Y. Yuan, Z. Xiong, and Q. Wang, “An Incremental Framework for Video-Based Traffic Sign Detection, Tracking, and Recognition," IEEE Transactions on Intelligent Transportation Systems, vol. 18, no. 7, pp. 1918-1929, Jul. 2017.

12. [12]Y. Li, X. Li, Y. Zhang, M. Liu, and W. Wang, "Anomalous Sound Detection Using Deep Audio Representation and a BLSTM Network for Audio Surveillance of Roads," IEEE Access, vol. 6, pp. 58043-58055, 2018. 
13. [13]T.-Y. Lee, V. Skvortsov, M.-S. Kim, S.-H. Han, and M.-H. Ka, "Application of \$W\$ -Band FMCW Radar for Road Curvature Estimation in Poor Visibility Conditions," IEEE Sensors Journal, vol. 18, no. 13, pp. 5300-5312, Jul. 2018.

14. [14]J. Lianghai, A. Weinand, B. Han, and H. D. Schotten, "Applying Multiradio Access Technologies for Reliability Enhancement in Vehicle-to-Everything Communication," IEEE Access, vol. 6, pp. 23079-23094, 2018.

15. [15]P. Foggia, N. Petkov, A. Saggese, N. Strisciuglio, and M. Vento, "Audio Surveillance of Roads: A System for Detecting Anomalous Sounds," IEEE Transactions on Intelligent Transportation Systems, vol. 17, no. 1, pp. 279-288, Jan. 2016.

16. [16]M. Fogue, P. Garrido, F. Martinez, J.-C. Cano, C. Calafate, and P. Manzoni, "Automatic Accident Detection: Assistance Through Communication Technologies and Vehicles," IEEE Vehicular Technology Magazine, vol. 7, no. 3, pp. 90-100, Sep. 2012.

17. [17]A. Majumder, L. Behera, and V. K. Subramanian, "Automatic Facial Expression Recognition System Using Deep Network-Based Data Fusion," IEEE Transactions on Cybernetics, vol. 48, no. 1, pp. 103-114, Jan. 2018.

18. [18]H. Park, D. Ahn, T. Park, and K. G. Shin, “Automatic Identification of Driver's Smartphone Exploiting Common Vehicle-Riding Actions," IEEE Transactions on Mobile Computing, vol. 17, no. 2, pp. 265-278, Feb. 2018.

19. [19]L. Guo, S. Manglani, Y. Liu, and Y. Jia, “Automatic Sensor Correction of Autonomous Vehicles by Human-Vehicle Teaching-and-Learning," IEEE Transactions on Vehicular Technology, vol. 67, no. 9, pp. 8085-8099, Sep. 2018.

20. [20]X. Wang, R. Jiang, L. Li, Y. Lin, X. Zheng, and F.-Y. Wang, "Capturing Car-Following Behaviors by Deep Learning," IEEE Transactions on Intelligent Transportation Systems, vol. 19, no. 3, pp. 910920, Mar. 2018.

21. [21]G. Li and W.-Y. Chung, "Combined EEG-Gyroscope-tDCS Brain Machine Interface System for Early Management of Driver Drowsiness," IEEE Transactions on Human-Machine Systems, vol. 48, no. 1, pp. 50-62, Feb. 2018.

22. [22]S. Noh and K. An, "Decision-Making Framework for Automated Driving in Highway Environments," IEEE Transactions on Intelligent Transportation Systems, vol. 19, no. 1, pp. 58-71, Jan. 2018

23. [23]W. Huang, G. Song, H. Hong, and K. Xie, "Deep Architecture for Traffic Flow Prediction: Deep Belief Networks With Multitask Learning," IEEE Transactions on Intelligent Transportation Systems, vol. 15, no. 5, pp. 2191-2201, Oct. 2014.

24. [24]D. Singh and C. K. Mohan, "Deep Spatio-Temporal Representation for Detection of Road Accidents Using Stacked Autoencoder," IEEE Transactions on Intelligent Transportation Systems, pp. $1-9,2018$.

25. [25]C. Jacobé de Naurois, C. Bourdin, A. Stratulat, E. Diaz, and J.-L. Vercher, "Detection and prediction of driver drowsiness using artificial neural network models," Accident Analysis \& Prevention, Dec. 2017.

26. [26]C. Jacobé de Naurois, C. Bourdin, A. Stratulat, E. Diaz, and J.-L. Vercher, "Detection and prediction of driver drowsiness using artificial neural network models," Accident Analysis \& Prevention, Dec. 2017.

27. [27]Z. Guo, Y. Pan, G. Zhao, S. Cao, and J. Zhang, "Detection of Driver Vigilance Level Using EEG Signals and Driving Contexts," IEEE Transactions on Reliability, vol. 67, no. 1, pp. 370-380, Mar. 2018.

28. [28]S. Taran and V. Bajaj, "Drowsiness Detection Using Adaptive Hermite Decomposition and Extreme Learning Machine for Electroencephalogram Signals," IEEE Sensors Journal, vol. 18, no. 21, pp. 8855-8862, Nov. 2018.

29. [29]Shyr-Long Jeng, Wei-Hua Chieng, and Hsiang-Pin Lu, "Estimating Speed Using a Side-Looking Single-Radar Vehicle Detector," IEEE Transactions on Intelligent Transportation Systems, vol. 15, no. 2, pp. 607-614, Apr. 2014.

30. [30]S. S. Thomas, S. Gupta, and V. K. Subramanian, "Event Detection on Roads Using Perceptual Video Summarization," IEEE Transactions on Intelligent Transportation Systems, vol. 19, no. 9, pp. 2944-2954, Sep. 2018.

31. [31]A. Filonenko, D. C. Hernandez, and K.-H. Jo, "Fast Smoke Detection for Video Surveillance Using CUDA," IEEE Transactions on Industrial Informatics, vol. 14, no. 2, pp. 725-733, Feb. 2018.

32. [32]K. Zaidi, M. B. Milojevic, V. Rakocevic, A. Nallanathan, and M. Rajarajan, "Host-Based Intrusion Detection for VANETs: A Statistical Approach to Rogue Node Detection," IEEE Transactions on Vehicular Technology, vol. 65, no. 8, pp. 6703-6714, Aug. 2016. 
33. [33]P. Kumari, J. Choi, N. Gonzalez-Prelcic, and R. W. Heath, "IEEE 802.11ad-Based Radar: An Approach to Joint Vehicular Communication-Radar System," IEEE Transactions on Vehicular Technology, vol. 67, no. 4, pp. 3012-3027, Apr. 2018.

34. [34]H. Dong, X. Wang, C. Zhang, R. He, L. Jia, and Y. Qin, "Improved Robust Vehicle Detection and Identification Based on Single Magnetic Sensor,” IEEE Access, vol. 6, pp. 5247-5255, 2018.

35. [35]D. Li, L. Deng, Z. Cai, B. Franks, and X. Yao, "Intelligent Transportation System in Macao Based on Deep Self-Coding Learning," IEEE Transactions on Industrial Informatics, vol. 14, no. 7, pp. 32533260, Jul. 2018.

36. [36]Z. Xu and Q. Shi, "Interference Mitigation for Automotive Radar Using Orthogonal Noise Waveforms," IEEE Geoscience and Remote Sensing Letters, vol. 15, no. 1, pp. 137-141, Jan. 2018.

37. [37]H. Lu, Y. Li, S. Mu, D. Wang, H. Kim, and S. Serikawa, "Motor Anomaly Detection for Unmanned Aerial Vehicles Using Reinforcement Learning," IEEE Internet of Things Journal, vol. 5, no. 4, pp. 2315-2322, Aug. 2018.

38. [38]L. Jin, M. Chen, Y. Jiang, and H. Xia, "Multi-Traffic Scene Perception Based on Supervised Learning," IEEE Access, vol. 6, pp. 4287-4296, 2018.

39. [39]Y. Li, Y. Qiao, and Y. Ruichek, "Multiframe-Based High Dynamic Range Monocular Vision System for Advanced Driver Assistance Systems," IEEE Sensors Journal, vol. 15, no. 10, pp. 5433 5441, Oct. 2015.

40. M. G. K. Raymond, "Multiple Target Tracking using FMCW Radar,” p. 11, 2016.

41. R. Gallen, A. Cord, N. Hautiere, E. Dumont, and D. Aubert, "Nighttime Visibility Analysis and Estimation Method in the Presence of Dense Fog," IEEE Transactions on Intelligent Transportation Systems, vol. 16, no. 1, pp. 310-320, Feb. 2015.

42. Dairi, F. Harrou, Y. Sun, and M. Senouci, "Obstacle Detection for Intelligent Transportation Systems Using Deep Stacked Autoencoder and \$k\$ -Nearest Neighbor Scheme,” IEEE Sensors Journal, vol. 18, no. 12, pp. 5122-5132, Jun. 2018.

43. X. Wang, L. Xu, H. Sun, J. Xin, and N. Zheng, "On-Road Vehicle Detection and Tracking Using MMW Radar and Monovision Fusion," IEEE Transactions on Intelligent Transportation Systems, vol. 17, no. 7, pp. 2075-2084, Jul. 2016.

44. [44]A. A. Malikopoulos, S. Hong, B. B. Park, J. Lee, and S. Ryu, "Optimal Control for Speed Harmonization of Automated Vehicles," IEEE Transactions on Intelligent Transportation Systems, pp. $1-13,2018$.

45. H. T. Nguyen, S.-W. Jung, and C. S. Won, "Order-Preserving Condensation of Moving Objects in Surveillance Videos," IEEE Transactions on Intelligent Transportation Systems, vol. 17, no. 9, pp. 2408-2418, Sep. 2016.

a. JJ.-Y. Kwak, B. C. Ko, and J. Y. Nam, "Pedestrian Tracking Using Online Boosted Random Ferns Learning in Far-Infrared Imagery for Safe Driving at Night," IEEE Transactions on Intelligent Transportation Systems, vol. 18, no. 1, pp. 69-81, Jan. 2017.

46. S. Contreras, S. Agarwal, and P. Kachroo, "Quality of Traffic Observability on Highways with Lagrangian Sensors," IEEE Transactions on Automation Science and Engineering, vol. 15, no. 2, pp. 761-771, Apr. 2018.

47. R. Sivakumar and D. H. Mangalam, "RADAR Based Vehicle Collision Avoidance System used in Four Wheeler Automobile Segments," vol. 5, no. 1, p. 8, 2014.

48. W.-J. Liao, Y.-C. Hou, C.-C. Tsai, T.-H. Hsieh, and H.-J. Hsieh, "Radar Cross Section Enhancing Structures for Automotive Radars," IEEE Antennas and Wireless Propagation Letters, vol. 17, no. 3, pp. 418-421, Mar. 2018.

49. M. E. Gadringer et al., "Radar target stimulation for automotive applications," IET Radar, Sonar \& Navigation, vol. 12, no. 10, pp. 1096-1103, Oct. 2018.

50. [51]J. Nyamagoud, "Real-time Obstacle Detection System for Needy Using RADAR," vol. 2, no. 4, p. 42 ,

51. [52]S. Brisken, F. Ruf, and F. Höhne, "Recent evolution of automotive imaging radar and its information content," IET Radar, Sonar \& Navigation, vol. 12, no. 10, pp. 1078-1081, Oct. 2018.

52. [53]C. Vasanelli, F. Bogelsack, and C. Waldschmidt, "Reducing the Radar Cross Section of Microstrip Arrays Using AMC Structures for the Vehicle Integration of Automotive Radars," IEEE Transactions on Antennas and Propagation, vol. 66, no. 3, pp. 1456-1464, Mar. 2018.

53. [54]M. U. K. Khan, H.-S. Park, and C.-M. Kyung, "Rejecting Motion Outliers for Efficient Crowd Anomaly Detection," IEEE Transactions on Information Forensics and Security, vol. 14, no. 2, pp. 541-556, Feb. 2019.

54. [55]D. Wang, X. Pei, L. Li, and D. Yao, "Risky Driver Recognition Based on Vehicle Speed Time Series," IEEE Transactions on Human-Machine Systems, vol. 48, no. 1, pp. 63-71, Feb. 2018. 
55. [56]L. Cui, G. Xie, Y. Qu, L. Gao, and Y. Yang, "Security and Privacy in Smart Cities: Challenges and Opportunities," IEEE Access, vol. 6, pp. 46134-46145, 2018.

56. [57]H. Luo et al., "Semantic Labeling of Mobile LiDAR Point Clouds via Active Learning and Higher Order MRF," IEEE Transactions on Geoscience and Remote Sensing, vol. 56, no. 7, pp. 3631-3644, Jul. 2018.

57. [58]H. Fan and H. Zhu, "Separation of Vehicle Detection Area Using Fourier Descriptor Under Internet of Things Monitoring," IEEE Access, vol. 6, pp. 47600-47609, 2018.

58. [59]R. Ravi, Y.-J. Lin, M. Elbahnasawy, T. Shamseldin, and A. Habib, "Simultaneous System Calibration of a Multi-LiDAR Multicamera Mobile Mapping Platform," IEEE Journal of Selected Topics in Applied Earth Observations and Remote Sensing, vol. 11, no. 5, pp. 1694-1714, May 2018.

59. [60]P. M. Dhulavvagol, R. Shet, P. Nashipudi, A. S. Meti, and R. Ganiger, "Smart Helmet with Cloud GPS GSM Technology for Accident and Alcohol Detection," in Cognitive Computing and Information Processing, vol. 801, T. N. Nagabhushan, V. N. M. Aradhya, P. Jagadeesh, S. Shukla, and C. M.L., Eds. Singapore: Springer Singapore, 2018, pp. 346-357.

60. [61]Z. Shao, J. Cai, and Z. Wang, "Smart Monitoring Cameras Driven Intelligent Processing to Big Surveillance Video Data," IEEE Transactions on Big Data, vol. 4, no. 1, pp. 105-116, Mar. 2018.

61. [62]H.-N. Wang, Y.-W. Huang, and S.-J. Chung, "Spatial Diversity 24-GHz FMCW Radar With Ground Effect Compensation for Automotive Applications," IEEE Transactions on Vehicular Technology, vol. 66, no. 2, pp. 965-973, Feb. 2017.

62. [63]B. Mandal, L. Li, G. S. Wang, and J. Lin, "Towards Detection of Bus Driver Fatigue Based on Robust Visual Analysis of Eye State," IEEE Transactions on Intelligent Transportation Systems, vol. 18, no. 3, pp. 545-557, Mar. 2017.

63. [64]L. Li, B. Qian, J. Lian, W. Zheng, and Y. Zhou, "Traffic Scene Segmentation Based on RGB-D Image and Deep Learning," IEEE Transactions on Intelligent Transportation Systems, vol. 19, no. 5, pp. 1664-1669, May 2018.

64. [65]Y.-C. Tung and K. G. Shin, "Use of Phone Sensors to Enhance Distracted Pedestrians' Safety," IEEE Transactions on Mobile Computing, vol. 17, no. 6, pp. 1469-1482, Jun. 2018.

65. [66]C. Hu, X. Bai, L. Qi, P. Chen, G. Xue, and L. Mei, "Vehicle Color Recognition With Spatial Pyramid Deep Learning," IEEE Transactions on Intelligent Transportation Systems, vol. 16, no. 5, pp. 2925-2934, Oct. 2015.

66. [67]Z. Peng, S. Gao, Z. Li, B. Xiao, and Y. Qian, "Vehicle Safety Improvement through Deep Learning and Mobile Sensing," IEEE Network, vol. 32, no. 4, pp. 28-33, Jul. 2018.

67. [68]Z. Peng, S. Gao, Z. Li, B. Xiao, and Y. Qian, "Vehicle Safety Improvement through Deep Learning and Mobile Sensing," IEEE Network, vol. 32, no. 4, pp. 28-33, Jul. 2018.

68. [69]J. Wang, H. Zheng, Y. Huang, and X. Ding, "Vehicle Type Recognition in Surveillance Images From Labeled Web-Nature Data Using Deep Transfer Learning," IEEE Transactions on Intelligent Transportation Systems, vol. 19, no. 9, pp. 2913-2922, Sep. 2018

69. [70]N. Kosaka and G. Ohashi, "Vision-Based Nighttime Vehicle Detection Using CenSurE and SVM," IEEE Transactions on Intelligent Transportation Systems, vol. 16, no. 5, pp. 2599-2608, Oct. 2015.

70. [71]H. Liu, T. Taniguchi, Y. Tanaka, K. Takenaka, and T. Bando, "Visualization of Driving Behavior Based on Hidden Feature Extraction by Using Deep Learning," IEEE Transactions on Intelligent Transportation Systems, vol. 18, no. 9, pp. 2477-2489, Sep. 2017.

71. [72]C.-T. Lin et al., "Voice Navigation Effects on Real-World Lane Change Driving Analysis Using an Electroencephalogram," IEEE Access, vol. 6, pp. 26483-26492, 2018.

72. [73]G. Krummenacher, C. S. Ong, S. Koller, S. Kobayashi, and J. M. Buhmann, "Wheel Defect Detection With Machine Learning," IEEE Transactions on Intelligent Transportation Systems, vol. 19, no. 4, pp. 1176-1187, Apr. 2018.

73. [74]R. Zhang et al., "WiFi Sensing-Based Real-Time Bus Tracking and Arrival Time Prediction in Urban Environments,” IEEE Sensors Journal, vol. 18, no. 11, pp. 4746-4760, Jun. 2018.

74. [75]J. K. Naufal et al., "A ${ }^{2}$ CPS: A Vehicle-Centric Safety Conceptual Framework for Autonomous Transport Systems," IEEE Transactions on Intelligent Transportation Systems, vol. 19, no. 6, pp. 19251939, Jun. 2018.

75. [76]A. Celesti, A. Galletta, L. Carnevale, M. Fazio, A. Lay-Ekuakille, and M. Villari, “An IoT Cloud System for Traffic Monitoring and Vehicular Accidents Prevention Based on Mobile Sensor Data Processing," IEEE Sensors Journal, vol. 18, no. 12, pp. 4795-4802, Jun. 2018.

76. [77]I. Kalamaras et al., "An Interactive Visual Analytics Platform for Smart Intelligent Transportation Systems Management," IEEE Transactions on Intelligent Transportation Systems, vol. 19, no. 2, pp. 487-496, Feb. 2018. 
77. [78]J. E. Siegel, D. C. Erb, and S. E. Sarma, "A Survey of the Connected Vehicle LandscapeArchitectures, Enabling Technologies, Applications, and Development Areas," IEEE Transactions on Intelligent Transportation Systems, vol. 19, no. 8, pp. 2391-2406, Aug. 2018.

78. [79]V. K. Kukkala, J. Tunnell, S. Pasricha, and T. Bradley, "Advanced Driver-Assistance Systems: A Path toward Autonomous Vehicles," IEEE Consumer Electronics Magazine, vol. 7, no. 5, pp. 18-25, Sep. 2018.

79. [80]R. P. Balandong, R. F. Ahmad, M. N. Mohamad Saad, and A. S. Malik, "A Review on EEG-Based Automatic Sleepiness Detection Systems for Driver," IEEE Access, vol. 6, pp. 22908-22919, 2018.

80. [81]"ACCIDENT - Statistical Year Book India 2017 | Ministry of Statistics and Program Implementation | Government Of India." [Online]. Available: http://mospi.nic.in/statistical-year-bookindia/2017/207. [Accessed: 17-Dec-2018].

81. [82]"National Highways Details - Ministry of Road Transport \& Highways, Government of India." [Online]. Available: http://morth.nic.in/index2.asp?slid=32\&sublinkid=12\&lang=1. [Accessed: 17-Dec2018].

82. [83]K. Schleinitz, T. Petzoldt, S. Kröling, T. Gehlert, and S. Mach, “(E-)Cyclists running the red light The influence of bicycle type and infrastructure characteristics on red light violations," Accident Analysis \& Prevention, vol. 122, pp. 99-107, Jan. 2019.

83. [84]A. Farid, M. Abdel-Aty, and J. Lee, "A new approach for calibrating safety performance functions," Accident Analysis \& Prevention, vol. 119, pp. 188-194, Oct. 2018.

84. J. Wu, H. Xu, Y. Zheng, and Z. Tian, "A novel method of vehicle-pedestrian near-crash identification with roadside LiDAR data," Accident Analysis \& Prevention, vol. 121, pp. 238-249, Dec. 2018.

85. J. Robbins, H. A. Allen, and P. Chapman, "Comparing car drivers' and motorcyclists' opinions about junction crashes," Accident Analysis \& Prevention, vol. 117, pp. 304-317, Aug. 2018.

86. S. A. Useche, L. Montoro, F. Alonso, and F. M. Tortosa, "Does gender really matter? A structural equation model to explain risky and positive cycling behaviors," Accident Analysis \& Prevention, vol. 118, pp. 86-95, Sep. 2018.

87. M. Pylkkönen et al., "Effects of alertness management training on sleepiness among long-haul truck drivers: A randomized controlled trial," Accident Analysis \& Prevention, vol. 121, pp. 301-313, Dec. 2018.

88. Sportillo, A. Paljic, and L. Ojeda, "Get ready for automated driving using Virtual Reality," Accident Analysis \& Prevention, vol. 118, pp. 102-113, Sep. 2018.

89. M. M. Rahman, L. Strawderman, M. F. Lesch, W. J. Horrey, K. Babski-Reeves, and T. Garrison, "Modelling driver acceptance of driver support systems," Accident Analysis \& Prevention, vol. 121, pp. 134-147, Dec. 2018.

90. R. C. McIlroy et al., "Who is responsible for global road safety? A cross-cultural comparison of Actor Maps," Accident Analysis \& Prevention, vol. 122, pp. 8-18, Jan. 2019.

91. Preece, A. Watson, S.-A. Kaye, and J. Fleiter, "Understanding the psychological precursors of young drivers' willingness to speed and text while driving," Accident Analysis \& Prevention, vol. 117, pp. 196-204, Aug. 2018.

92. ]S. G. Charlton and N. J. Starkey, "Transitions within a safe road system," Accident Analysis \& Prevention, vol. 121, pp. 250-257, Dec. 2018.

93. ]J. Liu, L. N. Boyle, and A. G. Banerjee, "Predicting interstate motor carrier crash rate level using classification models," Accident Analysis \& Prevention, vol. 120, pp. 211-218, Nov. 2018.

94. E. Kitali, P. Alluri, T. Sando, H. Haule, E. Kidando, and R. Lentz, "Likelihood estimation of secondary crashes using Bayesian complementary log-log model," Accident Analysis \& Prevention, vol. 119, pp. 58-67, Oct. 2018.

95. H. Al-libawy, A. Al-Ataby, W. Al-Nuaimy, and M. A. Al-Taee, "Modular design of fatigue detection in naturalistic driving environments," Accident Analysis \& Prevention, vol. 120, pp. 188-194, Nov. 2018.

96. Vingilis et al., "Young male drivers' perceptions of and experiences with YouTube videos of risky driving behaviours," Accident Analysis \& Prevention, vol. 120, pp. 46-54, Nov. 2018.

97. S. Dun and A. Z. Ali, "Seatbelts don't save lives': Discovering and targeting the attitudes and behaviors of young Arab male drivers," Accident Analysis \& Prevention, vol. 121, pp. 185-193, Dec. 2018.

98. . M. Wood, G. Isoardi, A. Black, and I. Cowling, "Night-time driving visibility associated with LED streetlight dimming," Accident Analysis \& Prevention, vol. 121, pp. 295-300, Dec. 2018.

99. J. R. Brubacher et al., "Police documentation of drug use in injured drivers: Implications for monitoring and preventing drug-impaired driving," Accident Analysis \& Prevention, vol. 118, pp. 200-206, Sep. 2018. 
100.D.Sivabalaselvamani et al., "Accident identification using fuzzy cognitive maps with adaptive nonlinear hebbian learning algorithm,"Journal of Information Systems \& eBusiness Network, ISSN: $1556-$ 5068, pp. 212-221.

101.]D.Sivabalaselvamani et al., "Supporting trust-based design for efficient transportation using intelligent transportation system (ITS) in VANETS", Asian Journal of Research in Social Sciences and Humanities, vol. 6, iss. 7, pp. 634-647.

102.D.Sivabalaselvamani et al., "A review analysis on VANETs: Security Issues and Challenges", International Journal of Scientific Development and Research, vol. 1, pp. 2544-263.

103.D.Sivabalaselvamani et al., "Convolution Neural Network based Specialized Restaurant Rating Using Facial Expression Detection”, IEEE International Conference on Inventive Computation Technologies, 2020,pp. 739-744. 